\title{
Molecular dynamics simulation of the relaxation of a grain boundary disclination dipole under ultrasonic stresses
}

\author{
A.A. Nazarov \\ aanazarov@imsp.ru \\ Institute for Metals Superplasticity Problems, RAS, 39 Khalturin street, 450001, Ufa, Russia
}

\begin{abstract}
Effect of oscillating tension-compression stresses on the atomic structure of a [112] tilt grain boundary (GB) containing a disclination dipole in nickel is simulated by molecular dynamics method. Initial system for simulations was constructed by joining together bicrystals containing symmetric tilt GBs $\Sigma=11 / 62.96^{\circ}$ and $\Sigma=31 / 52.20^{\circ}$, so the disclination dipole had a strength $\omega=10.76^{\circ}$. The as-constructed system was relaxed at temperature $T=300 \mathrm{~K}$ for time interval $150 \mathrm{ps}$. Then a sinusoidal uniaxial stress was applied along the normal to tilt axis in GB plane and its effect on the structure and energy of the bicrystal was studied. The period of the stress was equal to $160 \mathrm{ps}$, up to 5 cycles of deformation were applied. The model used is convenient for studies of dislocation absorption or generation by GBs, since only edge dislocations of a single slip system can nucleate and glide in each grain. The simulations have shown that the oscillating stress results in a generation of lattice dislocations by the GB, their glide across grains and sink at appropriate surfaces. The dislocations are nucleated at GB regions where the stress field of the disclination dipole facilitates this process, so the latter results in a compensation of the disclination stress fields and recovery of an equilibrium GB structure and energy. It is concluded that lattice dislocation generation by nonequilibrium GBs can be an underlying mechanism of a relaxation effect of ultrasound on the structure of heavily deformed metals.
\end{abstract}

Keywords: grain boundary, nonequilibrium structure, disclination, ultrasonic treatment, grain boundary recovery, molecular dynamics.

\section{Молекулярно-динамическое моделирование релаксации зер- нограничного дисклинационного диполя под воздействием ультразвуковых напряжений}

\author{
Назаров А.А. \\ aanazarov@imsp.ru \\ Институт проблем сверхпластичности металлов РАН, ул. Ст. Халтурина 39, 450001, Уфа, Россия
}

\begin{abstract}
Методом молекулярной динамики проведено моделирование влияния осциллирующих напряжений сжатия-растяжения на атомную структуру границы зерен (ГЗ) с осью наклона [112], содержащей дисклинационный диполь, в никеле. Исходная система для моделирования была построена путем стыковки бикристаллов, содержащих границы наклона $\Sigma=11 / 62.96^{\circ}$ и $\Sigma=31 / 52.20^{\circ}$, так что дисклинационный диполь имел мощность, равную $\omega=10.76^{\circ}$. Построенная таким образом система была подвергнута релаксации при температуре $T=300 \mathrm{~K}$ в течение времени 150 пс. Затем вдоль нормали к оси наклона в плоскости ГЗ было приложено синусоидальное одноосное напряжение, и изучено его влияние на структуру и энергию бикристалла. Период напряжений составлял 160 пс, были приложены до 5 циклов деформации. Используемая модель удобна для изучения поглощения или испускания дислокаций границами зерен, так как в каждом зерне могут зарождаться и скользить только краевые дислокации одной системы скольжения. Моделирование показало, что осциллирующее напряжение приводит к генерации границей решеточных дислокаций, их скольжению по зернам и стоку на соответствующих поверхностях. Дислокации зарождаются в областях ГЗ, в которых поле напряжений дисклинационного диполя облегчают этот процесс, поэтому последний приводит к компенсации полей напряжений дисклинационного диполя и возврату равновесной структуры и энергии ГЗ. Сделан вывод, что испускание дислокаций неравновесными ГЗ может быть основным механизмом релаксационного воздействия ультразвука на структуру сильно деформированных металлов.
\end{abstract}

Ключевые слова: граница зерен, неравновесная структура, дисклинация, ультразвуковая обработка, зернограничный возврат, молекулярная динамика. 


\section{Introduction}

Nonequilibrium state of grain boundaries (GBs) is a typical feature of the structure of heavily deformed materials such as, for example, ultrafine grained (UFG) metals processed by severe plastic deformation methods $[1,2]$. This state is mainly caused by extrinsic grain boundary dislocations (EGBDs) absorbed during plastic deformation and is characterized by long-range internal stresses and excess energy of the GBs [1]. Disclinations forming dipole or higher-order multipole configurations are the most common elements of the nonequilibrium GB structure $[1,3]$. Internal stresses induced by nonequilibrium GBs cause a low thermal stability and reduced ductility of UFG metals [2] and should be relaxed to enhance these properties. Recently, ultrasonic treatment (UST) has been shown to have a potential of improving the thermal stability, ductility and impact toughness of UFG materials [4-7]. Experimental studies have shown that under UST a relaxation of nonequilibrium GBs and related internal stresses occurs in UFG nickel processed by both high-pressure torsion [4] and equal-channel angular pressing [5-7]. Effect of oscillating stresses on plastically deformed nanocrystals was simulated by molecular dynamics on a model two-dimensional nanocrystal [8]. However, the use of a two-dimensional model cannot provide full information on the atomic mechanisms of structural changes in GBs under ultrasound. Therefore, the present work is devoted to a study of the behavior of a nonequilibrium GB under oscillating loading using a three dimensional model of a bicrystal.

\section{Model description and simulation procedure}

A bicrystal of nickel containing a tilt GB with misorientation axis [112] is chosen for simulations. In bicrystals of this system plastic deformation of the grains can occur by a nucleation and glide of edge dislocations of only one slip system, which have the lines parallel to the tilt axis. Recently, interactions of GBs with lattice dislocations in aluminum have been extensively studied on an example of this system [9].

Computational model was constructed as follows. First, two bicrystals with [112] tilt GBs $\Sigma=11 / 62.96^{\circ}$ and one with GB $\Sigma=31 / 52.20^{\circ}$ are prepared. At their ends all bicrystals are bounded by $\{111\}$ crystallographic planes or by planes normal to the GB plane (Fig. 1). In a geometric model of $\Sigma=31$ tilt boundary there are pairs of too close atoms near the GB plane, which are indicated in Fig. 1 by ellipses. These pairs are combined each to one atom lying in the GB plane. The bicrystals are put into contacts at their ends in a way that their GBs continue each other, so that material overlaps at one end of the $\Sigma=31$ bicrystal and voids at the other end form. By applying appropriate shears, these overlaps and voids are eliminated and $\{111\}$ planes of the bicrystals are fitted to each other. The composed bicrystal constructed by this way allows for applying periodic boundary conditions along the $x$ axis. Since displacement fields of disclinations involve not shears but rotations, the way of construction described results in a high energy state, which will relax during energy minimization, when appropriate displacements are established.
Atomic interactions were described by the embedded atom method (EAM) potential fitted to the lattice parameter $a_{0}=3.52 \AA$, cohesive energy $\varepsilon_{0}=4.45 \mathrm{eV}$ and other characteristics of nickel [10]. During simulations, periodic boundary conditions were applied along $x$ and $z$ directions. The cell sizes along these directions were equal to $H_{z}=3 / 2[112]=12.93 \AA$ and $H_{x}=30 h_{1}+6 h_{2}=139.26 \AA$, where $h_{1}$ and $h_{2}$ are the periods of tilt GBs $\Sigma=11$ and $\Sigma=31$, respectively. In the direction of $y$ axis the system had a finite size equal to $H_{y}=190 \AA$ and, respectively, open surfaces. After the relaxation without an applied stress surface layers with thickness $10 \AA$ Aere eliminated from both sides of the system for further simulations in order to exclude the surface steps arisen during this relaxation. In the rest system, next $10 \AA$ thickness layers are excluded from all energy calculations.

The system constructed by the procedure described above was equilibrated by molecular dynamics run according to the following protocol. First, 5000 steps energy minimization at zero temperature was done with atoms in the GB plane fixed at their positions. Second, the system was kept at temperature $300 \mathrm{~K}$ for 30000 steps at the same constraints. Then the constraints were removed and 40000 more steps were done at the same temperature. So, in total the system evolved in time interval 150 ps with time step $2 \mathrm{fs}$. The state so obtained was used for further simulations at the same temperature of $300 \mathrm{~K}$ by applying a sinusoidal stress along $x$ axis: $p_{\mathrm{x}}=p_{\mathrm{x} 0} \sin [(2 \pi / \tau) t]$, the period of which was equal to $\tau=160 \mathrm{ps}$. Coordinates of the particles were recorded in an $\mathrm{XYZ}$ format file with a time step $2 \mathrm{ps}$ in order to visualize the dynamics of structural changes during straining. Atomic energies were calculated prior to straining and after each loading cycle. In order to catch average positions of vibrating atoms at $300 \mathrm{~K}$ and calculate their potential energies more correctly, each of these states was finally subjected to a very short, 200 time steps energy minimization.

All simulations were carried out by molecular dynamics code XMD [11]. Visualization of the structures was done using the codes RasMol [12] and OVITO [13]. Simulations were carried out for two values of the stress amplitude $p_{x 0}=200$ and $500 \mathrm{MPa}$.

The results of simulations were analyzed in terms of observing the GB structure changes and lattice dislocation emission during deformation, changes of the simulation cell size $H_{x}$, and the change of the total energy of the system (except for surface layer atoms) with the number of cycles.

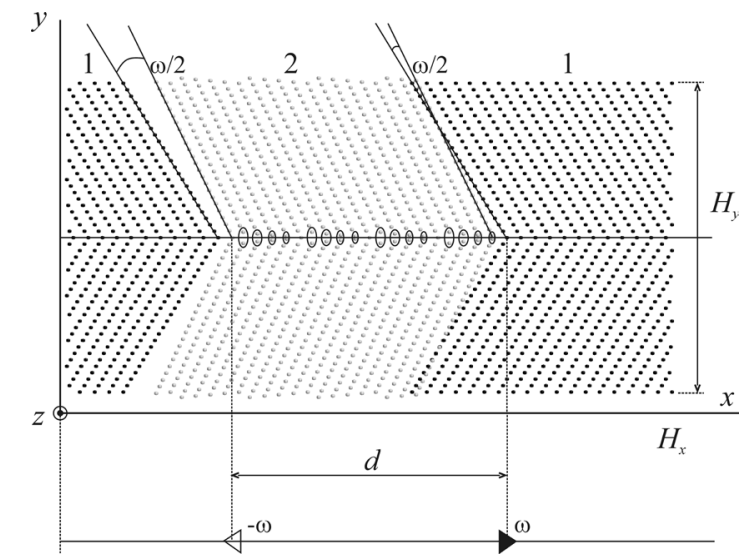

Fig. 1. Schematics of the construction of a computational cell. 


\section{Simulation results}

Atomic structure of the GB in the region of disclination dipole at temperature $T=300 \mathrm{~K}$ is presented in Fig. 2. One can see that parts of GB outside the disclination dipole consist of a sequence of one type structural units, which correspond to B-type structural units of favored GB $\Sigma=11$. Basing on the results of calculations of [112] tilt GB structures in another f.c.c. metal, aluminum [9], inside the dipole a GB structure of $\Sigma=31 \mathrm{~GB}$ consisting of structural units sequence $\mathrm{ABBBB}$ could be predicted, where $A$ is the structural unit of ideal lattice plane $\{110\}$. One can see that this is the case for the most part of this GB segment, but the leftmost A unit has transformed during relaxation. This transformation occurred by dislocation emission to the upper grain under the high internal stress induced by the disclination dipole. This dislocation is located on a distance of a few interatomic distances from the source structural unit and indicated by outlining the corresponding planes in the figure. Emission of the next dislocation to the bottom grain would complete the transformation of A unit to B one, but, presumably, the stresses were not enough for this. In the upper and bottom grains one can see two more lattice dislocations. Analysis shows that these are dislocations formed in the grains due to a highly nonequilibrium state of the initial structure made by only shears. Thus, the time interval of the MD protocol used to simulate the applied stress-free bicrystal was not enough to obtain a fully equilibrated system. However, this will not cause any disadvantage for further studies, since the three residual dislocations will immediately leave the bicrystal during loading.

Energy of defects in the system per unit GB area is equal to $\gamma=1.45 \mathrm{Jm}^{-2}$, while an equilibrium $\Sigma=11 \mathrm{~GB}$ has a significantly lower energy $\gamma_{\mathrm{eq}}=0.54 \mathrm{Jm}^{-2}$. Thus, due to the disclination dipole and three dislocations the excess energy of the system per unit GB area is equal to $\gamma_{\mathrm{ex}}=0.91 \mathrm{Jm}^{-2}$. We will take this as a reference for comparing the GB energy after oscillatory loading with different amplitudes.

During the tension stage of oscillatory loading the GB generates lattice dislocations. The dislocations are nucleated only at A-type structural units unless all of them are transformed into B-type units and the GB becomes an equilibrium $\Sigma=11$ tilt boundary. An example of dislocation generation is presented in Fig. 3a,b. In Fig 3a, a dislocation emission has transformed the A structural unit into B-unit and the dislocation is on a distance of a few atomic spacings from the source. After a lapse of 2 ps time the dislocation moved towards the surface. The surfaces are ideal sinks for dislocations and the latter never come back to the GB during compression stages of the applied stress. Thus, the sinusoidal uniaxial stress exerts an asymmetric effect on the GB structure resulting on its release from the extrinsic defects. This results in a relaxation of long-range stress fields and energy of the GB. This is proved by energy maps of the GB before cyclic treatment and after five cycles of straining under the stress $p_{x 0}$ $=500 \mathrm{MPa}$ (Fig. 4). One can see that in the initial state the GB induces significant long-range stresses, so many atoms in the grains also have high energies (Fig. 4a). After cycling the GB completely recovers a very regular structure typical for the $\Sigma=11$ GB (Fig. 4b). A calculation shows that the GB energy for this structure is equal to $\gamma_{\text {fin }}=0.61 \mathrm{Jm}^{-2}$ that is very close to the energy of equilibrium $\Sigma=11 \mathrm{~GB}, \gamma_{\mathrm{eq}}$. The slight difference is due to the fact that $\gamma_{\text {eq }}$ was calculated by a complete relaxation at $T=0 \mathrm{~K}$, while $\gamma_{\text {fin }}$ by only 200 steps of energy minimization after molecular dynamics run at $T=300 \mathrm{~K}$.

Effect of cyclic treatment depends on its amplitude. For $p_{x 0}=500 \mathrm{MPa}$ a complete relaxation occurs already during the first cycle, while at the stress amplitude $200 \mathrm{MPa}$ it is incomplete even after five cycles.

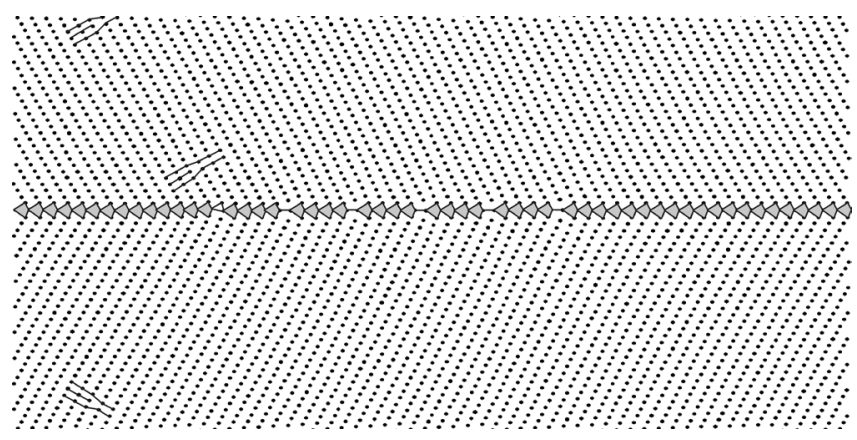

Fig. 2. Atomic structure of $\Sigma=11 \mathrm{~GB}$ containing a disclination dipole at $T=300 \mathrm{~K}$.

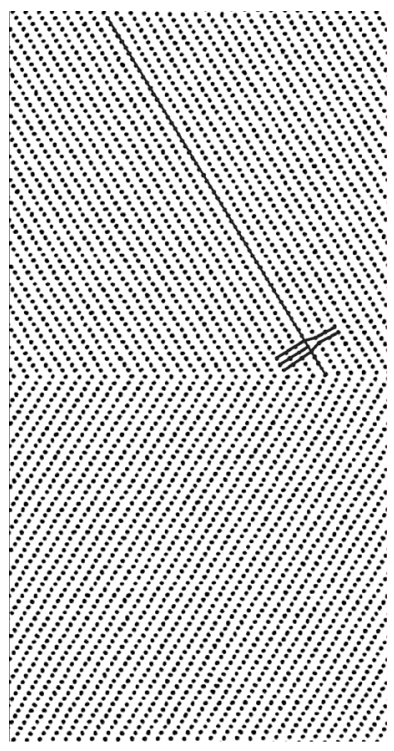

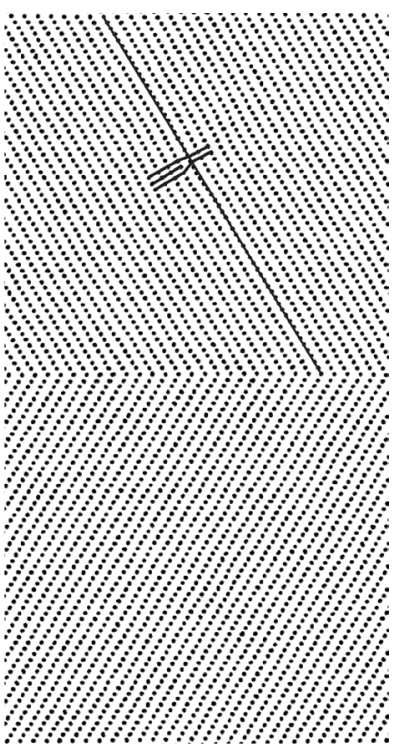

$\mathrm{b}$
Fig. 3. A typical example of lattice dislocation emission from a GB under cyclic loading.

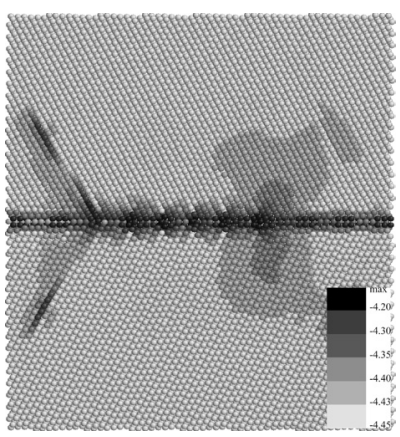

a

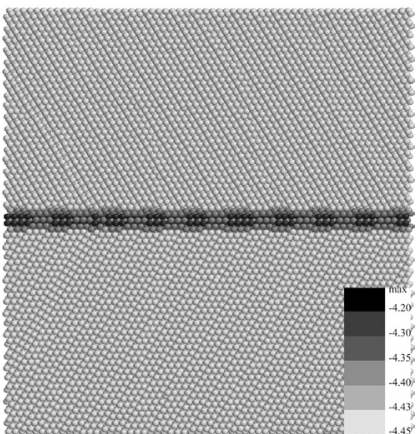

b
Fig. 4. Energy maps of a bicrystal containing a disclination dipole (a) and with a relaxed structure after five cycles of loading with stress amplitude $500 \mathrm{MPa}$ (b). 


\section{Discussion}

The present simulations show that a nonequilibrium GB containing a disclination-type defect can relax to its equilibrium structure under the effect of oscillating tensioncompression stresses. When the applied shear stress and internal stress induced by defects are added, the GB emits lattice dislocations to compensate the disclination dipole. This process is asymmetric, since the dislocations sink at the surfaces and are not returned back during the change of applied stress sign.

In a real polycrystalline material, there are at least two types of sinks for lattice dislocations generated from GBs: trapping by opposite GBs and annihilation or other stressscreening reactions with dislocations emitted from other GBs. One can expect that both these processes are irreversible and tend to reduce the overall internal stresses in material. Thus, the conclusion on the relaxation of nonequilibrium GB structure under ultrasonic treatment will be valid for real polycrystals too.

A similar study of the effect of UST on nonequilibrium GB has been carried out recently on an example of $\Sigma=$ $15 / 78.46^{\circ}$ tilt GB containing a disclination dipole with the strength about $15^{\circ}$ [14]. For this case, stress amplitudes as high as $1.7 \mathrm{GPa}$ were necessary for nucleation of dislocations. In the present case, stress amplitudes above $200 \mathrm{MPa}$ were enough for a complete relaxation of the disclination dipole in several loading cycles. Therefore, depending on geometrical parameters of GBs and the types and strength of extrinsic defects, which they contain, a broad spectrum of critical ultrasonic stress amplitudes for equilibration of GBs can exist.

\section{Conclusion}

The application of a periodic tension-compression stress to a deformed material can result in a relaxation of the nonequilibrium structure of its grain boundaries. This relaxation occurs by an emission of lattice dislocations by grain boundaries leading to a compensation of their extrinsic defects and can be considered as an underlying mechanism of the effect of ultrasonic treatment on the structure and properties of UFG materials processed by deformation methods.

Acknowledgements. This work was supported by the Russian Science Foundation under the grant No. 16-19-10129.

\section{References}

1. A.A. Nazarov, R.R. Mulyukov. Handbook of Nanoscience, Engineering, and Technology. Boca Raton, CRC Press. (2002) p. 22-1.

2. R.Z. Valiev, A.P. Zhilyaev, T.G. Langdon. Bulk Nanostructured Materials: Fundamentals and Applications. Hoboken, Wiley. (2013) 440 p.

3. V.V. Rybin. Large Plastic Deformations and Fracture of Metals. Moscow, Metallurgia. (1986). 224 p. (In Russian)

4. A.A. Nazarova, R.R. Mulyukov, V.V. Rubanik, Yu.V. Tsarenko, A.A. Nazarov. Phys. Metals Metallogr. 110, 574 (2010).

5. A.A. Samigullina, R.R. Mulyukov, A.A. Nazarov, A.A. Mukhametgalina, Yu.V. Tsarenko, V.V. Rubanik. Letters on Materials. 4, 52 (2014).

6. A.A. Samigullina, Yu.V. Tsarenko, V.V. Rubanik, V.A. Popov, V.N. Danilenko, R.R. Mulyukov. Letters on Materials. 2, 214 (2012).

7. A.A. Samigullina, A.A. Nazarov, R.R. Mulyukov, Yu.V. Tsarenko, V.V. Rubanik. Rev. Adv. Mater. Sci. 39, 14 (2014).

8. A.A. Nazarova, S.V. Dmitriev, Yu.A. Baimova, R.R. Mulyukov, A.A. Nazarov. Phys. Metals Metallogr. 111, 513 (2011).

9. T. Shimokawa. Phys. Rev. B 82, 174122 (2010).

10. S.M. Foiles, M.I. Daw and M.S. Baskes. Phys. Rev. B 33, 7983 (1986).

11. http://xmd.sourceforge.net/about.html.

12. http://www.openrasmol.org.

13. A. Stukowski. Modell. Simul. Mater. Sci. Eng. 18, 015012 (2010).

14. A.A. Nazarov. Rev. Adv. Mater. Sci., in press. 